\title{
Ciências Sociais no curso de Medicina: limites institucionais e pluralidade de disposições
}

\author{
Rafael Afonso da Silva ${ }^{1}$ \\ http://orcid.org/0000-0003-4701-3565 \\ Juan Carlos Aneiros Fernandez ${ }^{1}$ \\ http://orcid.org/0000-0001-8598-646X \\ Juliana Luporini do Nascimento ${ }^{1}$ \\ http://orcid.org/0000-0002-8420-1672 \\ Nelson Filice de Barros ${ }^{1}$ \\ http://orcid.org/0000-0002-5404-1516
}

\section{Resumo}

Estudos têm demonstrado a presença de distintas percepções de estudantes de medicina em relação ao valor das ciências sociais para sua formação. 0 objetivo deste artigo é refletir sobre essa diversidade por meio da análise de avaliações de estudantes de medicina sobre uma disciplina das ciências sociais em saúde. 0 artigo analisa avaliações de 69 estudantes coletadas por instrumento baseado na escala-Likert 10 com justificativa. A análise do material por núcleos de sentido permitiu identificar três grupos de avaliações coincidentes com as faixas de notas 0-3 (G1), 4-6 (G2) e 7-10 (G3). Os três grupos são atravessados pela percepção de um limite institucional para a aprendizagem na disciplina: a grade horária e o método de avaliação da maioria das disciplinas. Mas, em cada grupo, esse limite é assumido de maneira diversa, de acordo com a percepção da relevância das ciências sociais para a formação médica. A discussão dos resultados destaca, além do limite institucional mencionado: 1) a homologia entre o lugar (pré-clínico) que a organização curricular designa para as ciências sociais e a concepção sustentada majoritariamente pelos estudantes de G1, que, amparados no discurso da "eficiência especializada", compreendem as ciências sociais como um campo de saberes, por definição, estranho à prática médica; 2) a presença de discursos em G2 e G3 que se afastam dessa lógica por uma avaliação positiva dos conteúdos do módulo Saúde e Sociedade (SS), o que, considerada a proposta do módulo, sugere uma identificação desses estudantes com outras perspectivas, referências e modelos de educação e atuação médicas. Conclui-se com algumas questões suscitadas pela pesquisa e que demandam novas investigações e reflexões.

\section{Palavras-chave}

Ciências sociais - Educação médica - Epistemologia.

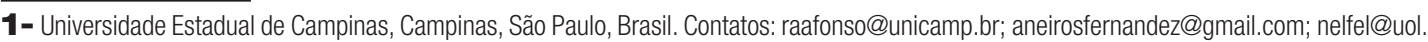
com.br; jluporini10@hotmail.com 


\section{Social Sciences in the Medicine course: institutional limits and plurality of dispositions}

\section{Abstract}

Studies have shown the presence of different perceptions of medical students in relation to the value of social sciences for their training. The purpose of this article is to reflect on this diversity by analyzing how medical student evaluate a discipline of Social Sciences in Health. The article analyzes 69 student assessments collected by instrument based on the 10 Likert scale with justification. Analyzing the material through core of meaning allowed to identify three groups of evaluations coinciding with grades $0-3$ (G1), 4-6 (G2) and 7-10 (G3). The three groups share the perception of an institutional limit in learning the discipline: the timetable and the evaluation method of most disciplines. But, in each group, this limit is seen differently, according to the perception of how relevant social sciences are for medical training. In addition to the mentioned institutional limit, the discussion of the results highlights: 1) the homology between the (pre-clinical) place assigned by the curriculum to the Social Sciences and the conception supported by most G1 students of G1, who, based on the "specialized efficiency" discourse, understand Social Sciences as a field of knowledge which are, by definition, foreign to medical practice; 2) the presence of speeches in G2 and G3 that depart from this logic exposing a positive evaluation of the contents of the Health and Society (SS) module, which, considering the module's proposal, suggests a identification of these students with other perspectives, references and models of medical education and performance. The article concludes with some questions raised by the research which demand new investigations and reflections.

\section{Keywords}

Social sciences - Medical education - Epistemology.

\section{Introdução}

"As ciências sociais são uma área tradicionalmente difícil de ser ensinada nos cursos de graduação da saúde”, lemos em um artigo dedicado à discussão dos desafios do ensino de ciências sociais em saúde (BARROS, 2016, p. 117). Essa percepção é compartilhada por diferentes estudos (NUNES et al., 2003; BENBASSAT et al., 2003; LITVA; PETERS, 2008; BARROS; NUNES, 2009; SATTERFIELD et al., 2010; BARROS, 2014) e constantemente referida por cientistas sociais que atuam na educação médica.

As razões da dificuldade, segundo tais estudos, são muito variadas, mas, de modo geral, se referem a uma "cultura epistêmica" hegemonizada pela configuração biomédica do saber e do fazer da profissão médica, e aos desdobramentos dessa hegemonia na produção 
dos “cenários epistêmicos” (KNNOR-CETINA, 1999)² da educação médica. Referindo-se, no contexto das escolas médicas, à desvalorização e à marginalização de temas, conhecimentos e especialistas do campo das ciências sociais em saúde, esses estudos têm apontado para processos que, de maneira mais ostensiva, repercutem na composição curricular (escassa presença das ciências sociais e concentração das disciplinas relacionadas a essa área no período "pré-clínico" da formação), na composição do corpo docente (reduzido número de cientistas sociais exercendo docência em cursos de medicina) e na própria "cultura do estudante de medicina", que passa a valorar negativamente o tempo investido em ciências sociais ao incorporar os discursos dominantes na escola médica.

No entanto, é preciso considerar que a presença das ciências sociais na educação médica, ainda que, em uma situação de "baixo status" (BARROS, 2016), é resultado de um movimento que não é apenas externo, mas também interno à medicina, indiciando a presença de vetores pluralizantes e de uma dinâmica conflitiva no contexto da própria "cultura epistêmica" da medicina. Vale lembrar que, ao longo do século XX, no que concerne ao ensino das ciências sociais em escolas médicas, houve uma transição progressiva, pelo menos no campo do discurso oficial, do princípio do "nice-to-know" para o princípio do "need-to-know" (BARROS, 2016), o que se afirma, internacionalmente, a partir do debate sobre a "responsabilidade social" das escolas médicas e, nacionalmente, culmina na proposição das ciências humanas e sociais como "eixo transversal" da formação médica nas Diretrizes Curriculares Nacionais para o curso de medicina (BRASIL, 2014).

Além disso, é demasiado determinista e reducionista sugerir que a "cultura do estudante de medicina" possa ser compreendida como mera derivação da "cultura" dominante na instituição de ensino, ainda que sua influência não possa ser subestimada. Como enfatizado por certas correntes da antropologia contemporânea (VIVEIROS DE CASTR0, 2012), a palavra "cultura", que se repete duas vezes no parágrafo acima, não deve ser encarada como designando um todo coerente, como um substantivo ou substância, mas como um complexo de agenciamentos e transformações. Mesmo no contexto de instituições "fechadas" ou de "monopolismos epistêmicos" (SANTOS, 2002, 2008), é preciso atentar para a pluralidade interna, para as resistências e para os efeitos divergentes do próprio dinamismo complexo das relações estratégicas que produzem as situações de poder.

Pensando nessa pluralidade e nesse dinamismo complexo, este estudo convida a considerar novamente o significado da "cultura do estudante de medicina" em sua relação com a dificuldade do ensino de ciências sociais na graduação em medicina. Ele se alinha com alguns estudos, ainda escassos, que têm constatado que tanto a "cultura do estudante de medicina”, como a relação desta com as ciências sociais em saúde, não podem ser consideradas no singular, nem de maneira estática (SATTERFIELD et al., 2010; BARROS et al., 2016). De modo mais específico, tais estudos têm demonstrado a presença de distintas percepções de estudantes de medicina em relação ao valor das ciências sociais

\footnotetext{
2- A noção de "cultura epistêmica" procura orientar a abordagem das questões macroepistêmicas da construção do conhecimento para a investigação de seus cenários práticos, focalizando os experimentos, textos, objetos, armações teóricas, habilidades incorporadas, interações comunitárias etc., que cercam a produção concreta de conhecimento pelos atores sociais, produzindo seu regime específico. Knnor-Cetina (1999) cunhou o termo "cenários epistêmicos" para referir-se a esses cenários práticos e a suas "maquinarias epistêmicas", com suas estruturas, processos, meios.
} 
para sua formação. Instigado por esses estudos e pelas interrogações que, a partir deles, se desdobram, este artigo tem como objetivo analisar um conjunto de avaliações de estudantes de medicina sobre uma disciplina do módulo 'Saúde e Sociedade' (SS), um módulo da área de ciências sociais em saúde pertencente ao currículo obrigatório do curso de medicina da Faculdade de Ciências Médicas (FCM) da Universidade Estadual de Campinas. A partir da constatação, por meio da análise, de que parte significativa dos discursos presentes nessas avaliações refere-se a percepções dos estudantes em relação ao sentido e ao valor das ciências sociais na formação médica, o artigo desenvolve algumas reflexões em torno da dificuldade de ensinar ciências sociais na graduação em medicina.

\section{Metodologia}

0 material analisado a seguir é composto de 69 avaliações, colhidas por meio de um instrumento elaborado com a finalidade de avaliar a recepção da proposta de uma disciplina do módulo SS pelos estudantes.

Por iniciativa de seus docentes, têm sido periodicamente coletadas expectativas e avaliações dos alunos das duas disciplinas do módulo SS. Pertencentes ao núcleo obrigatório do currículo do curso de medicina da FCM, essas disciplinas, semestrais e sequenciais, dirigidas aos estudantes do segundo ano, são as únicas voltadas para desenvolver diretamente temas e reflexões a partir de abordagens das ciências sociais. Além disso, são as únicas disciplinas desse núcleo cujas propostas são efetivamente elaboradas pelos profissionais da área de Ciências Sociais Aplicadas à Saúde da FCM. Em razão dessa disposição do arranjo curricular, as expectativas e avaliações dos discentes em relação a essas disciplinas constituem um material valioso do ponto de vista do objetivo acima enunciado.

Tendo em vista a finalidade do artigo, é importante expor a proposta da disciplina. Esta envolvia discussões orientadas para: a desnaturalização e historicização do modo hegemônico de considerar saúde, doença e cuidados; a percepção do caráter cultural e axiologicamente informado da medicina científıca ocidental; a introdução do tema da diversidade e da pluralidade de saberes etiológico-terapêuticos e de práticas de produção de saúde e cuidado invisibilizados e reprimidos por diversos mecanismos do modelo dominante. Essa proposta compreendia discussões instigadas pela leitura de textos de filósofos, antropólogos e sociólogos, como Foucault (2012), Martins (2004), Laplantine (1991) e Ortega (2008), mas se valia igualmente de outros recursos, como filmes, trabalhos em grupo e atividades em unidades de saúde, desenvolvidas na perspectiva das discussões dos temas abordados em sala de aula.

No ano em que ocorreu a disciplina (não explicitado para não haver identificação da turma), e que foi realizada coleta, a turma foi dividida em três subgrupos, cada qual sob a responsabilidade de um docente. Considerando que uma situação pontual de conflito produziu um viés muito específico, para além das reflexões pertinentes aos interesses deste artigo, nas avaliações de um dos subgrupos, este artigo analisa apenas as avaliações dos dois outros subgrupos (aqui denominados como Turma A e Turma B) - 69 avaliações de um total de 107 avaliações coletadas. 
0 instrumento de avaliação foi construído a partir da percepção da "importância de ter uma dimensão quantificável em relação a diferentes aspectos desenvolvidos no Módulo e também a necessidade de compreender com mais detalhes como cada um dos estudantes justifica sua avaliação" (BARROS et al, 2016). Basicamente, o instrumento (Imagem 1) visa a escutar os estudantes em relação às atividades da disciplina: aulas conceituais, filmes, textos e exercícios (questões acerca dos temas discutidos em aula). Cada uma das estratégias deve primeiro ser avaliada em uma escala de tipo Lickert (LICKERT, 1932), com gradação expressa em escala numerada de 0 a 10, que nos pareceu apropriada por ser uma escala numérica que os estudantes já estão habituados a manejar desde o ensino básico. Após a avaliação na escala, cada discente é convidado a expressar, na forma de justificativa, as razões das notas atribuídas a cada quesito. No final do instrumento, há um espaço reservado para o estudante expressar-se livremente em relação à disciplina ('Observações'). Não há necessidade de identificação do estudante, que é instruído a aproveitar o anonimato para escrever com toda a liberdade.

Imagem 1: Instrumento de avaliação

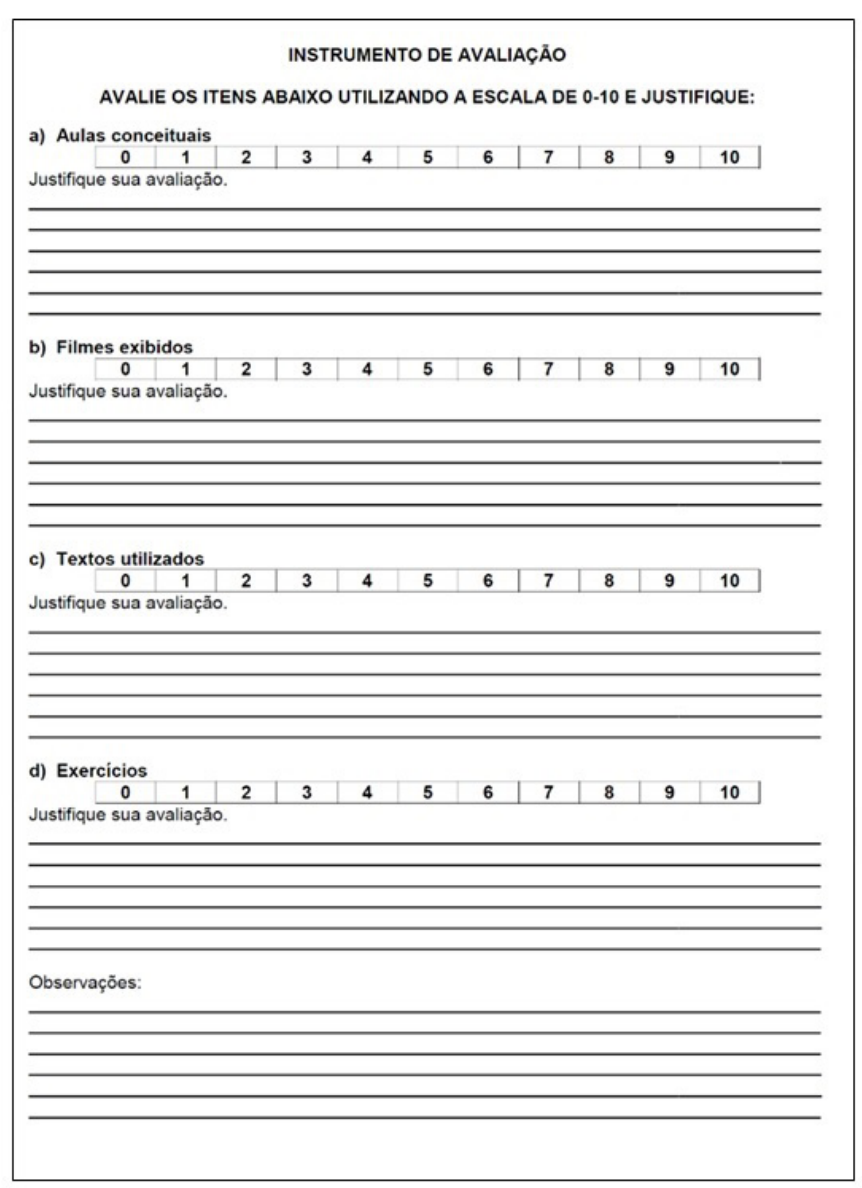


$\mathrm{Na}$ análise empreendida, a "dimensão quantificável” da avaliação foi manejada, sobretudo, com o interesse de facilitar a organização do material, mas a abordagem é eminentemente qualitativa, orientando-se para as experiências subjetivas dos alunos com a disciplina. Considerando os resultados em relação ao propósito da pesquisa, o instrumento foi adequado para compreender "as homogeneidades e as diferenciações internas do grupo", e a amostra foi suficiente para "propiciar reincidência e complementaridade das informações” (MINAYO, 2017, p. 4), cumprindo os requisitos de uma pesquisa qualitativa, que, como observa Minayo (2017, p. 2), "trabalha muito menos preocupada com os aspectos que se repetem e muito mais atenta com sua dimensão sociocultural que se expressa por meio de crenças, valores, opiniões, representações, formas de relação, simbologias, usos, costumes, comportamentos e práticas".

Para análise do material, recorremos à técnica de Análise Temática (MINAYO, 2006), buscando, na leitura das justificativas e comentários dos alunos, identificar núcleos de sentido (valorizados por sua representatividade e pertinência). Como havia, além das justificativas, a escala, exploramos a possibilidade de haver correspondência entre determinados núcleos de sentido e as notas atribuídas, o que permitiu, constatada a recorrência de certos núcleos de sentido dentro de certas faixas de notas, ordenar o material em três grupos, como explicitado a seguir.

Compreende-se que esta pesquisa se enquadra na situação descrita pelo inciso VII, do artigo primeiro da Resolução 510 do Conselho Nacional de Saúde, dispensando avaliação pelo sistema do Comitê de Ética em Pesquisa/Comitê Nacional de Ética em Pesquisa (CEP/CONEP). Os dados utilizados não permitem identificar sujeitos e houve o cuidado de suprimir o ano da coleta para que a turma não seja identificada.

\section{Resultados}

Após a digitação e leitura das avaliações, a primeira percepção foi de que havia uma consideração, em geral, muito positiva dos filmes (apreciados com notas que variavam entre 7 e 10), com algumas exceções. Por isso, considerando que os pontos atribuídos aos filmes tendiam a apagar a distância entre as avaliações, decidimos classificar os instrumentos de cada discente segundo a média entre os outros três itens (aulas conceituais, textos, exercícios de análise e síntese).

Uma primeira análise do material sugeria a presença de núcleos de sentido comuns ou recorrentes nas avaliações dos alunos cuja média entre os três itens recaía na faixa entre 0 e 3 pontos. Nas avaliações desses alunos, era marcante a percepção de irrelevância ou a dificuldade de compreender a relevância da disciplina para a formação médica. Isso permitiu estabelecer um ponto de partida para a análise do material. A partir daí, foi possível identificar dois outros grupos com núcleos de sentidos aproximados, o das avaliações com média entre 4 e 6 e o das avaliações com média entre 7 e 10. Foram estabelecidos, assim, três grupos de análise, quantitativamente representados na tabela abaixo. 
Tabela 1- Distribuição das avaliações segundo grupos de pontos na escala 0-10 e turma

\begin{tabular}{c:ccc:c:c} 
& & G1 (0-3) & G2 (4-6) & G3 (7-10) & Total de respostas \\
\hline Turma A & 14 alunos (38,9\%) & 10 alunos (27,8\%) & 12 alunos (33,3\%) & 36 \\
\hline Turma B & 8 alunos (24,2\%) & 15 alunos (45,5\%) & 10 alunos (30,3\%) & 33 \\
\hline Total & 22 alunos (31,9\%) & 25alunos (36,2\%) & 22 alunos (31,9\%) & $\vdots$ \\
\hline
\end{tabular}

Fonte: Elaborada pelos autores.

Observando a tabela, sobressai um número elevado de estudantes que avalia negativamente a disciplina (31,9\% do total de respondentes). Esses resultados, como as justificativas permitem sustentar, exprimem a insatisfação de uma grande parte dos estudantes em face da frustração das expectativas iniciais em relação à disciplina. Como expõe, de maneira concisa e direta, no campo 'Observações', um estudante cuja avaliação foi classificada no G1, "as expectativas foram frustradas, conforme foi previsto na palestra inicial do curso" $(\mathrm{S} 1)^{3}$.

A dificuldade e/ou extensão dos textos utilizados é a crítica mais recorrente no G1. Esse motivo aparece em 19 avaliações (86,4\%.). Os textos são considerados "muito complicados”, sobretudo, em razão da linguagem ou da terminologia. Para alguns alunos, eles são "inadequados" porque geram uma demanda impossível de ser realizada por conta da dinâmica do curso. A grade curricular e o horário livre "bastante restrito" tornariam inviável a leitura de textos de "alta complexidade", segundo algumas justificativas.

Para a compreensão desse ponto é necessária uma leitura do conjunto das avaliações do G1. 0 que as justificativas enunciam é que "inadequados" são os textos utilizados na disciplina SS, e não o exíguo tempo livre que os estudantes têm para lidar com as demandas do restante do curso. Assim, não chega a surpreender a indignação de um estudante que, no campo 'Observações', arremete contra a usurpação de tempo pelas disciplinas "tidas como humanizantes":

Matérias tidas como "humanizantes" ocupam a carga horária e diminuem o tempo que poderia ser usado para criar uma base acadêmica forte, sendo que conceitos humanizantes NÃO podem ser ensinados em uma aula. 0 corte na carga horária do ciclo básico resulta em menos tempo e direcionamento dos alunos [...]. (S2).

0 não reconhecimento da relevância da disciplina por 19 estudantes (86,4\% do total de estudantes do G1) decorreria, segundo 14 deles, do caráter filosófico, sociológico ou antropológico da disciplina e, consequentemente, de sua desconexão em relação à formação médica e à "realidade da profissão" ou sua "pouca relevância prática”. Alguns exemplos:

Discussões filosóficas que, além de não agregar muito ao conhecimento, são pouco interessantes e pouco objetivas. [...]. (S3 - 'Aulas conceituais' - nota 2).

\footnotetext{
3- Quando necessário, os alunos serão identificados, ao longo do texto, com as siglas S1 (sujeito 1), S2 (sujeito 2) e assim por diante.
} 
Aulas com conteúdo extremamente filosófico, incluindo discussões a partir das quais não se chega a consenso algum, tampouco a uma decisão. [...]. (S4 - 'Aulas conceituais' - nota 2).

As aulas conceituais têm pouco de medicina. São focadas unicamente em discussões filosóficas e antropológicas, de modo que se tornam desconexas do curso como um todo. Os temas da saúde da família e relação médico-paciente são abordados com uma visão pouco realista e relacionada à prática. (S5 - 'Aulas conceituais' - nota 2).

Os textos propostos são completamente inadequados a alunos de medicina. Têm apenas uma visão preconceituosa da prática médica, além de termos inacessíveis aos alunos. [...] Percebe-se que são direcionados a filósofos, cientistas sociais e antropólogos. (S6 -'Textos utilizados' - nota 1).

Textos, em sua maioria, muito longos e que pouco se relacionam com saúde e sociedade. Lendo muitos dos textos, sentia-me mais em uma aula de história do que em uma aula do curso médico. (S7 - 'Textos utilizados' - nota 2).

Além disso, assim como em uma parte das expectativas analisadas no artigo anterior (SILVA et al., 2018), é explicitada, em algumas avaliações, a concepção de que conhecimentos sociais ou culturais 'úteis' são óbvios ou mais facilmente apreensíveis pela observação e experiência prática direta, sem necessidade de mediação teórica, que apenas envolve o conhecimento óbvio e obviamente útil (segundo uma concepção de utilidade atada à de eficiência técnica) no invólucro de uma complexidade artificial e incompreensível. Um estudante sintetiza esse posicionamento ao afirmar que "não há melhor forma de estudar a sociedade que observando-a na prática”, traduzindo concretamente "observação prática" como visitas a "populações mais carentes" e hospitais ou experiências em serviços voluntários, o que, na sua visão, seria suficiente para que "compreendêssemos a amplitude do trabalho médico e seus efeitos sobre a sociedade" (S8).

Nas avaliações classificadas no G1, há certa convergência na avaliação negativa das 'Aulas conceituais' e dos 'Textos utilizados', embora a avaliação destes últimos seja tendencialmente mais negativa. Já no G2 amplia-se a distância entre as notas atribuídas aos dois itens, com uma avaliação bem mais positiva das 'Aulas conceituais'. Considerando as médias das notas atribuídas aos dois itens no G2, temos 6,8 e 4,1 na turma A e 6,4 e 3,9 na turma B.

Como no G1, um número elevado de estudantes (23 estudantes, ou seja, 92\% do total do G2) acusa a dificuldade e a extensão dos textos como um dos problemas da disciplina. Por outro lado, diversamente do G1, somente dois estudantes explicitam não perceber relevância nas discussões da disciplina para sua formação. Mesmo quando se denuncia a ênfase demasiadamente filosófica ou sociológica da disciplina (cinco avaliações), o problema é encarado como um problema de gradação (excesso) ou de linguagem, não como de total impertinência no contexto de um curso de medicina. Uma grande parte dos estudantes avalia os textos como "muito bons e ricos", como "pertinentes", como uma oportunidade de conhecer "autores muito bons" e de discutir um "conteúdo extremamente 
importante e interessante”. A avaliação negativa dos textos (na escala) é justificada pela dificuldade de absorvê-los, considerando sua complexidade e extensão, dentro de uma rotina acadêmica engessada pela grade horária do curso e pela saturação de demandas das outras disciplinas. As aulas conceituais, por sua vez, são valorizadas por seu conteúdo e pelo estilo crítico-reflexivo de abordagem por uma grande parte dos estudantes do G2. As críticas às aulas conceituais não recaem sobre seu conteúdo temático, mas sobre problemas didático-pedagógicos: manejo do tempo e/ou ausência de uma exposição mais pontual e didaticamente orientada dos textos.

Vejamos alguns comentários:

As aulas são muito interessantes por abordarem assuntos que muitas vezes caíram no esquecimento do estudante de medicina por falta de tempo. Apesar disso, as aulas são muito longas e maçantes. (S9 - 'Aulas conceituais' - nota 7).

Embora sejam textos muito bons e ricos, são textos de difícil compreensão, que necessitam de tempo para serem bem analisados e compreendidos. Em virtude de nossa carga horária, o tempo disponível para uma leitura correta e bem aproveitada do texto não é suficiente, comprometendo o aproveitamento das informações neles contidas. (S10 - 'Textos utilizados' - nota 6).

Gosto do objetivo da disciplina, de tentar nos tirar de uma visão unifocada (concentramo-nos apenas nas matérias decorativas [sic]) e nos devolver o pensamento crítico. Apesar disso, acho que as aulas deveriam ser menos pesadas, menos longas e mais reflexivas. (S11 - 'Observações').

Eu gosto da matéria, mas acho que tem que ter uma reformulação das aulas do curso inteiro, pois estamos inundados de matéria e coisas para fazer, o que torna difícil prestar atenção na aula (...). (S12 - 'Observações').

Percebe-se que há uma dificuldade comum, evidenciada pelos estudantes cujas avaliações classificamos no G2: o manejo de dois recursos limitados, tempo e energias intelectuais, no contexto de uma grade horária a qual, no semestre em questão, compreende 36 horas semanais de aula, em um momento do curso em que, como explicita S11, predominam disciplinas que valorizam a capacidade de reprodução 'decorada' de conteúdos transmitidos. A situação é ainda agravada pelo fato de que a reprovação em uma disciplina, em um curso com tal grade horária, implica, em geral, 'cair de turma', ou seja, não ser capaz de formar-se no mesmo ano em que a turma em que ingressou, o que, em geral, é muito valorizado pelos estudantes, acostumados, desde o primeiro ano de curso, a identificar-se como da turma 'ano tal'.

Embora sujeitos às mesmas circunstâncias institucionais acima mencionadas e relatando dificuldades para a leitura e a compreensão dos textos, os estudantes do G3 se mostram mais mobilizados pelas discussões da disciplina, recusando-se a avaliar a disciplina e, particularmente, os textos a partir da percepção negativa do tempo escasso. Diversamente do G2, esses estudantes valorizam não somente as aulas conceituais por promoverem "formas diferentes de pensar" ou introduzirem conteúdo "importante e 
inédito, não visto em nenhuma outra disciplina”, mas igualmente os textos, como ilustrado pelos comentários abaixo e pelas avaliações na escala:

A leitura, embora difícil, trouxe o contato com uma nova linguagem, menos técnica. Talvez a absorção do texto fosse melhor se houvesse uma contextualização do texto na semana anterior. (S13 - 'Textos utilizados' - nota 7).

Apesar de muitas vezes terem elevado grau de complexidade, os textos são bem elaborados e levam os alunos à reflexão. São, na maioria das vezes textos clássicos e atemporais, além de desafiadores, e é importante que os alunos tenham contato. (S14 - 'Textos utilizados' - nota 8).

A maioria dos textos desempenhou um papel de ampliar horizontes, especialmente o de Michel Foucault e os da 'Antropologia da doença'. [...]. (S15 - 'Textos utilizados' - nota 8).

Os textos eram muito bons, mas acredito que deveriam ser adicionados à bibliografia textos-base, mais simples, para auxiliar o entendimento dos textos mais complexos, uma vez que temos pouca base teórica na área. (S16 - 'Textos utilizados' - nota 9).

Malgrado a dificuldade de leitura testemunhada em algumas avaliações, os estudantes deste grupo não propõem a diminuição da carga de leitura ou a seleção de textos mais fáceis, mas a utilização de estratégias facilitadoras da leitura, como a contextualização prévia, a produção de guias de leitura ou a utilização de textos-base. Os textos e as aulas são valorizados justamente por sua diferença (ineditismo temático, "nova linguagem”, "formas diferentes de pensar") em relação ao curso como um todo. Até que ponto essa diferença é compreendida como complementar ou, ao contrário, como marcada por uma irredutível distância em relação às concepções hegemônicas na instituição, não é possível determinar a partir das justificativas dos alunos. 0 que é muito claro é que essa diferença é percebida como positiva, como possibilidade de "ampliar horizontes", como "desafiadora". Resumindo a análise empreendida, destacamos que:

- diversamente do que encontramos na análise das expectativas (MINAYO, 2006), identificamos não uma convergência ou homogeneidade, mas uma significativa diversidade de percepções e valorações em relação aos sentidos da aprendizagem no módulo 'Saúde e Sociedade' - o que corrobora os achados de outras pesquisas qualitativas empiricamente embasadas (SATTERFIELD, 2010; BARROS et al., 2016);

- entre as avaliações dos grupos 1, 2 e 3, examinadas nessa sequência, percebemos uma progressiva aproximação com as temáticas e reflexões das ciências sociais, no sentido do reconhecimento de sua relevância (apreendida em termos de especificidade da aprendizagem proporcionada) para a formação médica;

- há uma percepção geral, embora com distintos significados nos diferentes grupos, de um limite institucional para a aprendizagem nos termos propostos para o módulo: a grade horária e o sistema de avaliação da maioria das disciplinas. 


\section{Discussão}

As avaliações classificadas no G1 apelam para a noção de uma distinção rígida entre áreas de conhecimento, uma demarcação nítida entre o que cabe a "filósofos, cientistas sociais e antropólogos" e o que cabe em "uma aula do curso médico". A acusação de transposição dessas fronteiras se repete, mas é, sobretudo, o tráfico de abordagens filosóficas para o curso médico o que se destaca. Levando em conta o equacionamento comum entre filosofia e exercício contemplativo e o modo frequentemente negativo pelo qual tal exercício é considerado em um contexto dominado pela "libido dominandi" (MAFFESOLI, 1988) da 'razão instrumental', essa ênfase no caráter filosófico da disciplina parece dar acesso a outra crítica: a falta de realismo ou de relevância prática das discussões da disciplina.

Esse conjunto de considerações expressa uma recusa a abordagens supostamente construídas fora do território epistemológico da medicina científica. Não obstante componham há décadas o conteúdo programático ministrado nacional e internacionalmente - no curso de medicina da FCM, por exemplo, o ensino dos aspectos socioantropológicos do processo saúde-doença-cuidado acontece desde 1963 (NUNES, 2000) - e tenham alcançado, em nosso país, as Diretrizes Curriculares Nacionais para o Ensino de Medicina (BRASIL, 2014), abordagens filosóficas ou das ciências humanas, antropológicas, sociológicas ou históricas são avaliadas como alheias ao curso de medicina.

Essas avaliações expõem, majoritariamente, o que podemos denominar, na companhia de Bauman (1999), de "obsessão de separar". A separação constitui o fundamento da "excelência local, especializada", embutida nas "maneiras modernas de fazer as coisas" (BAUMAN, 1999, p. 22), excelência garantida pela própria focalização localista, cindida, da especialização, como poder de 'manter de lado' e, portanto, de encobrir os problemas gerados por sua própria ação fora de seu foco ou, como sói dizer, fora de sua alçada, poder de ocultar o fato de que "a ação induzida pelo especialista está fadada a desequilibrar tanto o ambiente sistêmico da ação quanto as relações entre os próprios atores”, ao desconsiderar o contexto interativo maior (BAUMAN, 1999, 227).

0 tráfico de abordagens filosóficas ou sociológicas para o curso médico é compreendido pelos estudantes do G1, e com razão, como algo que compromete os parâmetros da "excelência local, especializada”, ao demandar não somente a consideração de refugos produzidos pela separação e seus efeitos iatrogênicos, como também dos dispositivos de sua produção como refugo. Esse tráfico, como diz um aluno, desvia energia e usurpa tempo (recursos escassos) da construção de "uma base acadêmica forte" (S2). 'Desconexo', 'pouco objetivo', 'pouco realista', 'irrelevante' são termos que expressam estratégias discursivas (dos alunos) para colocar o refugo novamente em seu lugar, ou seja, fora.

0 tráfico de abordagens filosóficas ou sociológicas perturba a certeza cognitiva do mecanismo classificatório que permite a gestão localizada de um conjunto selecionado de dimensões possíveis da existência, produzidas como problemas e campo de ação da "excelência local, especializada" da medicina. Os estudantes mais identificados com esse mecanismo e sua 'naturalidade' ou mais ciosos dos resultados alcançados em seu esforço sistemático de incorporar seus parâmetros cognitivos e perfil comportamental 
ou de suprimir sua própria resistência a eles, esses estudantes, certamente, tenderão a desaprovar, como ridículo, inútil ou duvidoso ("preconceituoso", escreve S6), o que é introduzido por esse tráfico.

As disciplinas do módulo SS, pelo menos no formato assumido nos últimos anos, têm, sem dúvida, a pretensão de fazer um convite para olhar ou entrar na área cinzenta, de incerteza cognitiva e prática, que cerca o mundo das maneiras e verdades domésticas, naturalizadas, em todos os campos do conhecimento, área cinzenta em que emergem outras maneiras de fazer as coisas, com outras subjetividade e objetividades, outra "cosmopolítica", como diria Viveiros de Castro (2012), diversa daquela permitida ou produzida pelos saberes arrogantes e, também, ingênuos, que se tornaram hegemônicos ao longo dos últimos dois séculos (SANTOS, 2002, 2008; FERREIRA, 2003) e das práticas informadas unicamente por essas hegemonias.

O convite para reconhecer e conviver com a incerteza, a ambivalência, a complexidade e a diversidade (BAUMAN, 1999; SANTOS, 2002, 2008; MORIN, 2007) é um convite difícil em qualquer contexto, mas é ainda mais difícil no campo da medicina. Nesse campo, o lugar para a incerteza é, sobretudo, empregado retoricamente, sempre referido ao aforismo de Sir William Osler - "a medicina é a ciência da incerteza e a arte da probabilidade" - e cogitado pelos que já têm uma experiência profissional em algumas áreas, mas, quando se trata de estudantes nos anos iniciais do curso, parece não haver lugar legítimo para a incerteza sobre o que fazer. Além disso, mesmo quando a incerteza é reconhecida pelos expertos nesse campo, ela o é, de ordinário, em relação a possibilidades e limites identificados em um exercício epistemológico autocentrado, isto é, sem levar em conta a existência de outros saberes e, portanto, de outras modalidades de agência e intervenção eficazes em saúde ${ }^{4}$ ou desconsiderando as incertezas que decorrem das assimetrias morais emergentes da diversidade cultural (GEERTZ, 2000) e suas possíveis implicações na construção do horizonte normativo das práticas e dos processos de tomada de decisão no exercício da medicina. Já a certeza sobre o que fazer é a certeza que se produz ao determinar o que se pode ou se deve 'manter de lado', quando se determina sobre o que afirmar a competência e o controle da prática médica, suprimindo a ambivalência e afastando as implicações derivadas da complexidade pela redução dos problemas a marcos analíticos e conceituais estritamente delimitados, procedimento que Santos (2008) explicita como característico do "pensamento ortopédico".

A percepção de que "as aulas conceituais têm pouco de medicina" (S5) ou de que os textos "pouco se relacionam com saúde e sociedade" (S7) remete a alguma concepção subjacente de medicina e da relação entre saúde e sociedade. Embora não explicitada nas avaliações, podemos relacionar sem dificuldade tal concepção com a perspectiva que permeia as expectativas, a qual é informada pela biologização e pela patologização

4- É interessante considerar aqui a seguinte reflexão de Santos (2008, p. 27-28): "0 saber só existe como pluralidade de saberes, tal como a ignorância só existe como pluralidade de ignorâncias. As possibilidades e os limites de compreensão e de ação de cada saber só podem ser conhecidas na medida em que cada saber se propuser uma comparação com outros saberes. (...) Os limites e as possibilidades do que um dado tipo de saber permite conhecer sobre uma dada experiência humana decorrem de esta ser também conhecida por outros saberes que esse saber ignora. Os limites e as possibilidades de cada saber residem, assim, em última instância, na existência de outros saberes e, por isso, só podem ser explorados e valorizados na comparação com outros saberes". 
da saúde, pela cisão entre sujeito (o representante dos saberes e técnicas da medicina institucionalizada) e objeto (paciente, população) e pela apreensão da "sociedade" sob a rubrica da falta, da insuficiência, da incapacidade de agência:

'Sociedade' designa, nesse sentido, um território saneado de agência (pelo menos no campo da saúde), enquanto 'saúde' designa um território saneado de pluralidade. A pluralidade é o 'outro' (no singular) que os agenciamentos legítimos em ‘saúde’ devem reconduzir aos marcos reguladores (conceituais e prático-instrumentais) dos saberes válidos ('corretos' ou 'melhores') em saúde. A ação em saúde é a prerrogativa de sujeitos que já não falam a partir de sua própria diferença (social e cultural), mas a partir da autoridade de saberes produzidos no território epistemológico e prático unificado pela medicina científica institucionalizada. (SILVA et al., 2018, p. 26).

No contexto dessa perspectiva, a medicina aparece como agente de um regime de saber-poder (FOUCAULT, 2000, 2012) baseado na objetivação/isolamento de saúde/ doença como um conjunto de processos biológicos, e estendido na forma de uma série de práticas orientadas pelos estatutos de normalidade gerados nesse processo de objetivação/ isolamento (CASTIEL; ALVAREZ-DARDET, 2007; CAPONI, 2003; LAPLANTINE, 1991). Nessa proposta objetivante, trata-se não de excluir a questão da relação entre "saúde e sociedade", mas de assumi-la como questão de um conjunto de fatores abordáveis de maneira tão objetivada como os processos biológicos pela episteme dominante nas ciências da saúde.

É a partir dessa proposta reducionista e objetivante que se procura legitimamente 'separar' o que se pode ou se deve 'manter dentro' ou 'manter de lado' na formação médica. 0 aprendizado 'excelente' dentro dos parâmetros da "excelência local, especializada” da medicina parece depender da concentração no que deve ser mantido 'dentro'. Esse é o foco da maioria das outras disciplinas pelas quais o aluno já passou e deve passar durante a graduação.

A lógica da 'separação' é a lógica da grade curricular e do reconhecimento institucional da aquisição da 'excelência' para o exercício profissional da medicina e, por assim ser, acaba por alcançar também as avaliações de G2 e G3, ainda que nestes casos, mais em razão de certo cálculo estratégico por parte dos estudantes. A concentração no que deve ser mantido 'dentro' se torna razão de sobrevivência, em face do ritmo de uma grade horária inflada e de seus fluxos tensos (de exigências e avaliações), de modo que o estudante é impelido a conformar-se com a situação de autonomia contrariada e a regular seu tempo dedicando-se, em cada período, apenas aos conhecimentos ou competências imediatamente submetidos a avaliação ou, ainda, aos meios e atividades extras (como a participação em ligas de especialidade médica ou em outras agremiações estudantis) que beneficiem o acúmulo de 'capital social' no âmbito da rede local de relações sociais vinculadas à corporação médica.

Deste modo, embora convencidos da relevância da disciplina SS, os estudantes classificados no G2 e no G3 sentem-se constrangidos a escolher entre investir tempo e energia em uma disciplina que, a despeito de seu "conteúdo extremamente importante e interessante", tem baixo reconhecimento institucional - como refere a literatura a respeito do ensino de ciências sociais em escolas de medicina (LITVA; PETERS, 2008; BARROS, 2016) 
e os autores do texto podem afirmar em relação à sua própria experiência - ou nas disciplinas que, além de gozarem de outro status institucional, enredam os estudantes em uma sucessão ininterrupta de provas que demandam apropriação 'decorada' de conteúdos extensos e complexos. Diante desse quadro, é muito razoável, do ponto de vista da sobrevivência dentro da instituição, que haja um subinvestimento de tempo e energia na disciplina SS, e é compreensível que os estudantes demonstrem certa irritabilidade a demandas contrárias a essa economia estratégica de recursos. Para os estudantes do G2, o impedimento para uma percepção mais positiva da disciplina e um envolvimento mais ativo com sua proposta não se deve tanto a uma subjetivação da "cultura epistêmica" dominante em escolas médicas (como no G1), quanto a uma normatividade institucional objetivamente imposta pela grade horária e pela estratégia pedagógica prevalente na formação.

Mas, tão importante quanto detectar esses limites, é destacar que, quando valorizam outros conteúdos e formatos para a educação médica, aproximando-se das temáticas e reflexões das ciências sociais em saúde, os alunos classificados em G2 e G3 desafiam os pressupostos daquela lógica que delimita o que se deve 'manter dentro' ou 'manter de lado'. A imagem de “ampliação de horizontes", empregada por um aluno na avaliação da disciplina, pode ser lida como uma valorização de um alargamento ou borramento dessas fronteiras, em benefício da inclusão de outros conhecimentos e modelos de atuação prática na formação médica, favorecendo a produção de outros fundamentos éticos, estéticos e epistemológicos para o exercício da profissão.

No entanto, quando se consideram seus "cenários epistêmicos" majoritários, é importante registrar que há grande probabilidade de que essas diferenças (que se relacionam, em última instância, aos sentidos, valores e modelos de atuação do profissional da medicina) sejam desprovidas de oportunidades para seu desenvolvimento longitudinal, ao longo da formação, podendo não alcançar o espaço de formação prática da profissão. Deste modo, na medida em que são 'mantidos de lado' na maioria dos "cenários epistêmicos" da escola médica, em particular daqueles em que ocorre a aprendizagem das tecnologias e habilidades práticas do exercício da profissão, essas diferenças podem ser 'mantidas dentro' pelos estudantes apenas como possibilidades idealizadas ou virtuais. Essas possibilidades não são atualizadas no campo de produção da "cultura prática" do exercício da profissão, isto é, não se convertem em sentidos e disposições adquiridos no envolvimento com a "taskscape" ("tarefagem") dos settings práticos da profissão, não se transformam em "habilidades incorporadas de percepção e ação” (INGOLD, 2010, p. 21).

Tal reflexão nos reconduz a um texto sociológico já clássico no campo de análise da "carreira moral" do estudante de medicina durante seu percurso na escola médica, Boys in white (BECKER et al., 1961). Um dos aspectos discutidos nesse livro é o destino do idealismo durante a formação. A conclusão do estudo é que a concentração nos assim chamados "aspectos técnicos" dos casos clínicos na formação (na verdade, em uma dimensão biomedicamente recortada dos "aspectos técnicos" dos casos), faz com que o estudante assuma uma postura "cínica" durante a formação, ocultando o idealismo que o conduziu ao curso ou adiando sua realização para o exercício profissional futuro.

Uma pergunta não colocada nesse livro clássico é: o que acontece com o idealismo, quando sua realização depende de "habilidades de percepção e ação" que não foram 
desenvolvidas e incorporadas ao longo da formação? Ou, voltando à discussão acima, não será o distanciamento entre o 'mantido dentro' e o 'mantido de lado', reposto na relação entre ‘básico' e 'clínico’, um dos aspectos da formação médica que colabora para a produção daquele "cinismo" evidenciado em Boys in white? 0 estudo que sustenta este artigo não permite responder a essas perguntas, mas permite construí-las, o que produz uma demanda de novas investigações.

\section{Considerações finais}

Na discussão dos resultados, destacam-se três aspectos. 0 primeiro é a homologia entre o lugar (pré-clínico) que a organização curricular designa para as ciências sociais e a concepção sustentada majoritariamente pelos estudantes de G1, que, amparados no discurso da "eficiência especializada", compreendem as ciências sociais como um campo de saberes, por definição, estranho à prática médica. A presença desse discurso revela que o já referido princípio do "need-to-know" pode não ser absorvido ou compreendido pelas novas gerações e, mais que isso, que disposições contrárias são produzidas dentro da escola médica. Como os resultados da pesquisa permitiram apreender, tal discurso indica a presença de valores e signos compartilhados e, nesse sentido, de espaços de interação e de redes intercomunicantes na sua produção/circulação dentro das escolas médicas.

0 segundo aspecto é a presença de discursos em G2 e G3 que se afastam dessa lógica por uma avaliação positiva da disciplina SS, o que, quando se considera sua proposta, com seu questionamento de parâmetros epistemológicos e práticos dominantes no exercício da medicina e com sua valorização da pluralidade de saberes e práticas presentes no campo da saúde, sugere uma identificação com outras perspectivas, referências e modelos de educação e atuação médicas. Em certo sentido, a existência dessas diferenças entre os estudantes aponta para uma possibilidade inscrita em toda cultura viva, que, nos termos de Wagner (2010), se desenvolve em um jogo complexo de "simbolizações convencionais" e "simbolizações diferenciantes". No caso em tela, embora esses posicionamentos dos estudantes de G2 e G3 encontrem respaldo também em certas correntes de "simbolizações convencionais" ou "institucionalizadas", como nas próprias Diretrizes Curriculares, é possível que, no contexto das experiências concretas de ensinoaprendizagem, as "simbolizações diferenciantes" (orientadas para modos não hegemônicos de exercício da profissão médica) sejam neutralizadas ou despotencializadas pela ausência de oportunidades efetivas de desenvolvimento de habilidades práticas correspondentes.

0 terceiro aspecto refere-se ao limite estrutural identificado pelos estudantes, sobretudo do G2 (mas também do G3), para uma relação mais intensa com o módulo SS: a carga horária do curso e o modo de avaliação dominante na instituição. Enquanto a ausência de tempo livre, o estado de esgotamento permanente e o sofrimento psíquico - fenômenos típicos da "sociedade do desempenho/cansaço" (HAN, 2017) - são frequentemente relatados pelos alunos, uma menor implicação ou um menor investimento no módulo SS participa de um manejo estratégico dos alunos para não sucumbirem ao cansaço ou, pior (do ponto de vista da "sociedade do desempenho"), fracassarem em face das demandas do curso. 
Gostaríamos de concluir expondo algumas questões emergentes desta investigação: como construir "cenários epistêmicos" na formação médica que superem a "obsessão de separar" que ainda a informa, favorecendo o cruzamento e a ecologização de saberes, experiências e práticas entre cientistas sociais "in medicine" e médicos? Que estruturas, processos e meios são necessários para que esse cruzamento e essa ecologização ocorram igualmente nos settings práticos da aprendizagem da profissão médica, permitindo que os "conteúdos" das ciências sociais em saúde se convertam em ou participem da produção de ferramentas e "habilidades incorporadas de percepção e ação" do graduado em medicina? Como criar contextos pedagógicos e estruturas curriculares que valorizem e expandam o tempo livre dos estudantes de medicina e que favoreçam sua autonomia no processo de aprendizagem? São perguntas que não podem ser adequadamente respondidas neste texto e que demandam outras investigações, bem como o envolvimento das comunidades acadêmicas das escolas médicas na reflexão acerca desses desafios.

\section{Referências}

BARROS, Nelson Filice. 0 ensino das ciências sociais em saúde: entre 0 aplicado e 0 teórico. Ciência \& Saúde Coletiva, Rio de Janeiro, v. 19, n. 4, p. 1053-1066, 2014.

BARROS, Nelson Filice. As ciências sociais na educação médica. São Paulo: Hucitec, 2016.

BARROS, Nelson Filice; NUNES, Everardo Duarte. Sociologia, medicina e a construção da sociologia da saúde. Revista de Saúde Pública, São Paulo, v. 43, n. 1, p. 169-175, 2009.

BARROS, Nelson Filice et al. Resposta em escala seguida de justificativa: uma avaliação triangulada. In: CATRIB, Ana Maria Fontenelle; BRASIL, Cristina Cesar Praça; CARLO, Daniele de Araújo (org.). Avaliação de processos educacionais em saúde: tendências e inovações. Fortaleza: UECE, 2016. p. 140-158.

BAUMAN, Zygmunt. Modernidade e ambivalência. Rio de Janeiro: Jorge Zahar, 1999.

BECKER, Howard Saul et al. Boys in white: student culture in medical school. Chicago: University of Chicago. 1961.

BENBASSAT, Jochanan et al. Overcoming barriers to teaching the behavioral and social sciences to medical students. Academic Medicine, Novo Mexico, v. 78, n. 4, p. 372-380, 2003.

BRASIL. Ministério da Educação. Conselho Nacional de Educação. Câmara de Educação Superior. Resolução CNE/CES n. 3, de 20 de junho de 2014. Institui diretrizes curriculares nacionais do curso de graduação em medicina e dá outras providências. Diário Oficial da União, Brasília, DF, Seção 1, n. 117, p. 8-11, 23 jun. 2014.

CAPONI, Sandra. Saúde como abertura do risco. In: CZERESNIA, Dina (org.). Promoção da saúde: conceitos, reflexões e tendências. Rio de Janeiro: Fiocruz, 2003. p. 55-77. 
CASTIEL, Luis David; ALVAREZ-DARDET, Carlos. La salud persecutoria. Revista de Saúde Pública, São Paulo, v. 41, n. 3, p. 461-466, 2007.

FERREIRA, Luiz Otávio. Medicina impopular: ciência médica e medicina popular nas páginas dos periódicos científicos (1830-1840). In: CHALHOUB, Sidney et al. (org.). Artes e ofícios de curar no Brasil. Campinas: Unicamp, 2003. p. 101-122.

FOUCAULT, Michel. A ordem do discurso. São Paulo: Loyola, 2000.

FOUCAULT, Michel. Microfísica do poder. São Paulo: Graal, 2012.

GEERTZ, Clifford. Nova luz sobre a antropologia. Rio de Janeiro: Zahar, 2000.

HAN, Byung-Chul. Sociedade do cansaço. Petrópolis, Vozes, 2017.

INGOLD, Timothy. Da transmissão de representações à educação da atenção. Educação, Porto Alegre, v. 33, n. 1, p. 6-25, 2010.

KNORR-CETINA, Karin. Epistemic cultures: how the science make knowledge. Cambridge: Harvard University, 1999.

LAPLANTINE, François. Antropologia da doença. São Paulo: Martins Fontes, 1991.

LICKERT, Rensis. A technique for the measurement of attitudes. Archives of Psychology, Bethel Park, n. 140, p. 5-55, 1932. Disponível em: https://legacy.voteview.com/pdf/Likert_1932.pdf. Acesso em: 15 maio 2018.

LITVA, Andrea, PETERS, Sarah. Exploring barriers to teaching behavioral and social sciences in medical education. Medical Education, London, v. 42, n. 3, p. 309-314, 2008.

MAFFESOLI, Michel. Elogio da razão sensível. 1. ed. Petrópolis: Vozes, 1988.

MARTINS, André. Filosofia e saúde: métodos genealógico e filosófico-conceitual. Cadernos de Saúde Pública, São Paulo, v. 20, n. 4, p. 109-118, 2004.

MINAYO, Maria Cecília de Souza. Amostragem e saturação em pesquisa qualitativa: consensos e controvérsias. Revista Pesquisa Qualitativa, Curitiba, v. 5, n. 7, p. 01-12, 2017.

MINAYO, Maria Cecília de Souza. 0 desafio do conhecimento: pesquisa qualitativa em saúde. São Paulo: Hucitec, 2006.

MORIN, Edgar. Introdução ao pensamento complexo. Porto Alegre: Sulina, 2007.

NUNES, Everardo Duarte. Ensinando ciências sociais em uma escola de medicina: uma história de um curso (1965-90). História, ciências, saúde - Manguinhos, Rio de Janeiro, v. 6, n. 3, p. 631-657, 2000. 
NUNES, Everardo Duarte et al. 0 ensino das ciências sociais nas escolas médicas: revisão de experiências. Ciência \& Saúde Coletiva, Rio de Janeiro, v. 8, n. 11, p. 209-225, 2003.

ORTEGA, Francisco. 0 corpo incerto: corporeidade, tecnologias médicas e cultura contemporânea. Rio de Janeiro: Garamond, 2008.

SANTOS, Boaventura de Sousa. A filosofia à venda, a douta ignorância e a aposta de Pascal. Revista crítica de Ciências Sociais, Coimbra, v. 80, p. 11-43, 2008.

SANTOS, Boaventura de Sousa. Para uma sociologia das ausências e uma sociologia das emergências. Revista crítica de Ciências Sociais, Coimbra, v. 63, p. 237-280, 2002.

SATTERFIELD, Jason M. et al. Creating an ideal social and behavioral sciences curriculum for medical students. Medical Education, London, v. 44, n. 12, p. 1194-1202, 2010.

SILVA, Rafael Afonso da et al. Ciências sociais em saúde, educação médica e a concepção intervencionista e colonial da prática médica. Trabalho, Educação e Saúde, v. 16, n. 1, p. 39-56, 2018.

VIVEIROS DE CASTRO, Eduardo. 'Transformação' na antropologia, transformação da 'antropologia'. Mana, Rio de Janeiro, v. 8, n. 1, p. 151-171, 2012.

WAGNER, Roy. A invenção da cultura. São Paulo: Cosac Naify, 2010.

Recebido em: 10.06.2019

Revisado em: 02.10.2019

Aprovado em: 12.11.2019

Rafael Afonso da Silva é cientista social, mestre e doutor em Sociologia pela Universidade Estadual de Campinas (Unicamp), profissional de apoio a ensino, pesquisa e extensão da Faculdade de Ciências Médicas da Unicamp.

Juan Carlos Aneiros Fernandez é cientista social, professor doutor da Faculdade de Ciências Médicas da Unicamp e professor permanente do Programa de Pós-Graduação em Saúde Coletiva da mesma instituição.

Juliana Luporini do Nascimento é cientista social, mestre em ciências e doutora em Saúde Coletiva, professora doutora da Faculdade de Ciências Médicas da Unicamp.

Nelson Filice de Barros é professor livre-docente da Faculdade de Ciências Médicas da Unicamp e coordenador do Laboratório de Práticas Alternativas, Complementares e Integrativas em Saúde. 